\title{
Stress-mediated generation of deleterious ROS in healthy individuals - role of cytochrome c oxidase
}

\author{
Rabia Ramzan ${ }^{1,2} \cdot$ Sebastian Vogt ${ }^{1,2} \cdot$ Bernhard Kadenbach $^{3}$ \\ Received: 7 January 2020 / Revised: 24 March 2020 / Accepted: 30 March 2020 / Published online: 20 April 2020 \\ (C) The Author(s) 2020
}

\begin{abstract}
Psychosocial stress is known to cause an increased incidence of coronary heart disease. In addition, multiple other diseases like cancer and diabetes mellitus have been related to stress and are mainly based on excessive formation of reactive oxygen species (ROS) in mitochondria. The molecular interactions between stress and ROS, however, are still unknown. Here we describe the missing molecular link between stress and an increased cellular ROS, based on the regulation of cytochrome c oxidase (COX). In normal healthy cells, the "allosteric ATP inhibition of COX" decreases the oxygen uptake of mitochondria at high ATP/ADP ratios and keeps the mitochondrial membrane potential $\left(\Delta \Psi_{\mathrm{m}}\right)$ low. Above $\Delta \Psi_{\mathrm{m}}$ values of $140 \mathrm{mV}$, the production of ROS in mitochondria increases exponentially. Stress signals like hypoxia, stress hormones, and high glutamate or glucose in neurons increase the cytosolic $\mathrm{Ca}^{2+}$ concentration which activates a mitochondrial phosphatase that dephosphorylates COX. This dephosphorylated COX exhibits no allosteric ATP inhibition; consequently, an increase of $\Delta \Psi_{\mathrm{m}}$ and ROS formation takes place. The excess production of mitochondrial ROS causes apoptosis or multiple diseases.
\end{abstract}

Keywords Stress $\cdot$ Reactive oxygen species (ROS) $\cdot$ Mitochondrial membrane potential $\cdot$ Cytochrome c oxidase $\cdot$ Allosteric ATP inhibition

\section{Introduction}

Psychosocial stress is known to cause cardiovascular diseases including increased heart rate, high blood pressure, energy mobilization, decreased insulin sensitivity, and endothelial dysfunction [1]. In a multi-cohort study involving 90,164 individuals, the risk of coronary heart disease was $41 \%$ higher in individuals with the two work stressors effort-reward imbalance and job strain [2]. Although the molecular basis of these diseases is very complex, the role of oxidative distress [3], in particular increased reactive oxygen species (ROS) production in

Bernhard Kadenbach

kadenbach@staff.uni-marburg.de

1 Cardiovascular Research Lab, Biochemical Pharmacological Center, Philipps-University Marburg, Karl-von-Frisch-Strasse 2, D-35043 Marburg, Germany

2 Department of Heart Surgery, The University Hospital of Giessen and Marburg, Baldinger Strasse 1, D-35043 Marburg, Germany

3 Department of Chemistry/Biochemistry, Philipps-University Marburg, Hans-Meerwein-Strasse, D-35032 Marburg, Germany mitochondria, seems to predominate [4-7]. Furthermore, multiple other diseases like cancer, hypertension, atherosclerosis, ischemia/reperfusion injury, neurodegenerative diseases like Alzheimer's disease and Parkinson's disease, rheumatoid arthritis, diabetes mellitus, and mitochondrial diseases have also been related to excessive ROS production in cells [8-11]. But, the detailed molecular sequence of reactions relating psychosocial stress as well as other stressors (hypoxia, xenobiotica, stress hormones, etc.) to increased ROS generation in mitochondria remained unclear. ROS mainly include the superoxide radical anion $\cdot \mathrm{O}_{2}{ }^{-}$(half-life $\approx 5$ s), hydrogen peroxide $\mathrm{H}_{2} \mathrm{O}_{2}$, and the hydroxyl radical $\cdot \mathrm{OH}$ (half-life $\approx 10^{-9} \mathrm{~s}$, formed by the Haber-Weiss reaction: $\cdot \mathrm{O}_{2}^{-}+\mathrm{H}_{2} \mathrm{O}_{2} \rightarrow \mathrm{O}_{2}+\cdot \cdot \mathrm{OH}+\mathrm{OH}^{-}$, catalyzed by $\mathrm{Fe}^{3+}$-ions). In cells, the mitochondrially produced $\cdot \mathrm{O}_{2}^{-}$is rapidly converted into $\mathrm{H}_{2} \mathrm{O}_{2}$ by the action of superoxide dismutases present in the matrix and the intermembrane space [12].

Here we describe a molecular mechanism, which represents the missing link between psychosocial stress/other stressors and the generation of cellular distress [3], based on excessive ROS production in mitochondria. This mechanism includes a stress-induced increase of cytosolic calcium, 
followed by dephosphorylation of cytochrome c oxidase (COX), loss of "allosteric ATP inhibition of COX," increase of mitochondrial membrane potential $\Delta \Psi_{\mathrm{m}}$, and the formation of ROS.

\section{ROS have signaling functions}

ROS (mainly $\bullet \mathrm{O}_{2}^{-}$and hydrogen peroxide $\mathrm{H}_{2} \mathrm{O}_{2}$ ) are produced in cells by various oxidases that react with molecular oxygen, e.g., NADPH oxidases and xanthine oxidase. Go et al. [13] have listed 31 human cellular oxidases generating $\mathrm{H}_{2} \mathrm{O}_{2}$. Cytochrome c oxidase, however, is the exception and does not release ROS during the reduction of $\mathrm{O}_{2}$ to two molecules of $\mathrm{H}_{2} \mathrm{O}$ [14]. ROS are efficiently quenched in normal cells by the antioxidative defense systems including superoxide dismutases, glutathione peroxidase, and catalase $[15,16]$. However, small amounts of ROS do have signaling functions in cells, e.g., acting in the maintenance of physiological functions - a process termed redox biology [4]. In a review, the mechanisms and targets of ROS impacting on cellsignaling proteins (NF-KB, MAPKs, Keap1-Nrf2-ARE, and PI3K-Akt), ion channels and transporters $(\mathrm{Ca}(2+)$ and $\mathrm{mPTP})$, and modifying protein kinase and ubiquitination/proteasome system have been described [17]. The influence of ROS on metabolic processes such as proteasome function, autophagy, and general inflammatory signaling is discussed by Forrester et al. [18]. In various cancers, ROS have pro-tumorigenic signaling and thus maintain resistance to apoptosis [19]. In normal relaxed cells, low amounts of harmless ROS are maintained by similar activities of its generating and degrading enzymes.

\section{ROS generation in mitochondria}

Almost all energy consumed by aerobic organisms, including heat production and the synthesis of ATP, is produced by fireless burning of food with molecular oxygen $\left(\mathrm{O}_{2}\right)$. ATP is synthesized by oxidative phosphorylation in mitochondria, including the respiratory chain which is composed of complexes I (NADH dehydrogenase), II (succinate dehydrogenase), III (ubiquinol:cytochrome c oxidoreductase or cytochrome $\mathrm{bc}_{1}$ ), IV (COX), and the two-electron carriers: ubiquinone and cytochrome c. Electron transport in complexes I, III, and IV is coupled with the translocation of protons across the inner mitochondrial membrane from the matrix into the intermembrane space creating a membrane potential $\Delta \Psi_{\mathrm{m}}$ and a $\mathrm{pH}$ gradient $\Delta \mathrm{pH}_{\mathrm{m}}$ (predominantly $\Delta \Psi_{\mathrm{m}}$ ), which are used by complex V (ATP synthase) to produce ATP from ADP and phosphate. The oxygen accepting enzyme of the respiratory chain is COX, the rate-limiting step of mitochondrial respiration in vivo $[20,21]$.
High amounts of ROS are produced in mitochondria under certain conditions, in particular after ischemia and reperfusion in the heart and brain [22]. ROS production occurs in particular at high $\mathrm{NADH} / \mathrm{NAD}^{+}$ratios and at a high mitochondrial membrane potential $\Delta \Psi_{\mathrm{m}}[23,24]$. In addition to various other sites in mitochondria, ROS are mainly produced from complexes I and III [24-28]. Overproduction of ROS could lead to oxidative damage of lipids, DNA, and proteins [29, 30].

In isolated mitochondria from rat liver or pigeon heart respiring with NAD-linked substrates or succinate, approximately $2 \%$ of the total oxygen utilization at state 4 leads to the generation of $\mathrm{H}_{2} \mathrm{O}_{2}$ [31]. At respiratory state 4 , all of the phosphate acceptor, i.e., ADP, is converted into ATP and the isolated mitochondria develop a $\Delta \Psi_{\mathrm{m}}$ of $180-200 \mathrm{mV}$ [32, 33]. At the active state 3 , where ADP is still available, $\Delta \Psi_{\mathrm{m}}$ has a lower value. Above $140 \mathrm{mV}$, however, the production of ROS increases exponentially with increasing $\Delta \Psi_{\mathrm{m}}$, as measured in isolated mitochondria [34-36], and with the purified and reconstituted complex III [37]. High $\Delta \Psi_{\mathrm{m}}$ values, accompanied by an increased deleterious ROS production, can be decreased by uncoupler of oxidative phosphorylation. In fact, the use of uncouplers has been proposed as a powerful antiaging strategy [38] and as a cytoprotective strategy under conditions of oxidative stress including diabetes, drug-resistance in tumor cells, ischemia-reperfusion injury, or aging [39]. These results prove the influence of high $\Delta \Psi_{\mathrm{m}}$ on deleterious mitochondrial ROS production.

In contrast to isolated mitochondria, the mitochondria of relaxed cells in vivo have low $\Delta \Psi_{\mathrm{m}}$ values, i.e., between 100 and $130 \mathrm{mV}$ (references in [40]), at which only very low amounts of ROS are produced [36]. In vivo mitochondria are submerged within $2-10 \mathrm{mM}$ ATP with ATP/ADP ratios of 100-1000 of "free nucleotides," as calculated from ${ }^{31} \mathrm{P}$ NMR measurements [41]. This means that in vivo the ATP/ ADP ratio is always above the half-maximal inhibition of COX activity by the "allosteric ATP inhibition of COX" (see below), which is ATP/ADP $=28[42,43]$. The frequently cited high number of $2 \%$ of total oxygen utilization in mitochondria leading to $\mathrm{H}_{2} \mathrm{O}_{2}$ (ROS) generation [31] corresponds to isolated mitochondria without the allosteric ATP inhibition of COX. The exact value of the low cellular ROS production in vivo, however, is difficult to estimate $[23,44]$.

\section{Allosteric ATP inhibition of COX}

The unique properties of $\mathrm{COX}$ account for its regulatory functions. These are tissue- and developmental-specific isoforms of 6 of the 10 nuclear-encoded "supernumerary" subunits [45, 46], which are tightly bound to three mitochondrially synthesized catalytic subunits I-III [14]; reversible phosphorylation [47-49] and acetylation [50]; binding of various other proteins 
[51] including the formation of "respirasomes" [52-55]; and reversal binding of small molecules and ions such as ADP or ATP [56], diiodothyronine [57], and calcium or sodium [58].

The kinetic analysis of oxygen uptake of COX at increasing ferrocytochrome $\mathrm{c}$ concentrations in the presence of ADP and ATP revealed a sigmoidal shape of the curve with complete inhibition of activity at high ATP/ADP ratios and low amounts of substrate, contrasting the hyperbolic curve in the presence of ADP or without additions [43]. These nucleotides bind to the matrix domain of the transmembraneous subunit IV $[42,43,59]$, representing one of the ten ADP-binding sites in COX from the heart, seven of which are exchanged by ATP at high ATP/ADP ratios [60]. The sigmoidal shape of the kinetics indicates cooperativity of two binding sites for ferrocytochrome c (Hill coefficient 2 [43]), suggested to be located at the two monomers of a dimeric enzyme. The X-ray crystal structure of bovine heart COX revealed a homodimeric enzyme [61]. Each COX monomer contains only one cytochrome $\mathrm{c}$ binding site [62]. This "allosteric ATP inhibition of COX" keeps $\Delta \Psi_{\mathrm{m}}$ at low values $(<130 \mathrm{mV})$, due to feedback inhibition of COX activity by ATP at high ATP/ADP ratios. High ATP/ADP ratios already exist at low $\Delta \Psi_{\mathrm{m}}$, because the rate of ATP synthesis by ATP synthase is saturated and maximal at $100-120 \mathrm{mV}$ [63]. Therefore, further increase of $\Delta \Psi_{\mathrm{m}}$ by proton pumping of complexes I, III, and IV of the respiratory chain is inhibited by the ATP inhibition of COX, the ratelimiting enzyme of the respiratory chain in vivo [20,21]. High ATP/ADP ratios of $100-1000$ were measured in vivo by ${ }^{31} \mathrm{P}-$ NMR in relaxed cells [41]. The inhibitory effect of ATP on $\Delta \Psi_{\mathrm{m}}$ has also been measured directly in isolated rat liver mitochondria using a tetraphenyl phosphonium electrode [64]. The low ROS production in mitochondria of living cells under relaxed conditions [23] is thus explained by the allosteric ATP inhibition of COX [45, 46, 65, 66].

The allosteric ATP inhibition of COX, however, is not always found with isolated mitochondria and is usually lost during purification of the enzyme [67]. It could be restored by incubation of purified COX with protein kinase A (PKA) and cAMP and can be abolished by incubating again with $\mathrm{Ca}^{2+}$ and protein phosphatase $1[68,69]$. The phosphorylation site at COX was identified towards the intermembrane side of subunit I [68], which contains heme a and the oxygen binding site heme $\mathrm{a}_{3} / \mathrm{Cu}_{\mathrm{B}}$ [14]. The reversible switching on of this mechanism by cAMP and switching off by $\mathrm{Ca}^{2+}$ was also shown recently using intact isolated rat heart mitochondria [70]. The results with intact mitochondria coincide with the data obtained previously using isolated enzyme $[68,69]$.

In addition to ATP inhibition of COX activity by the phosphorylated enzyme (postulated phosphorylation site: Ser-441 in subunit I [68]), COX activity is also inhibited by its substrate cytochrome $\mathrm{c}$ when it is phosphorylated at serine- 47 . After dephosphorylation of cytochrome c during ischemia, this attenuation of COX activity is abolished [71].

\section{Stress and calcium signaling}

Calcium represents a universally important messenger in all multicellular life [72]. The cytosolic concentration of calcium in normal resting cells is very low (about $0.1 \mu \mathrm{M}$ ) and is more than 10,000 times lower than its concentration in blood plasma (about $2 \mathrm{mM}$ ). Numerous extracellular signals from hormones to growth factors are transduced to intracellular $\left[\mathrm{Ca}^{2+}\right]$ i spikes that are amplitude and frequency encoded [73-75]. In addition, they are highly localized within cells [76].

The low cytosolic $\mathrm{Ca}^{2+}$ concentration of about $0.1 \mu \mathrm{M}$ in normal relaxed cells is generally correlated with a low $\Delta \Psi_{\mathrm{m}}$ of 100-120 mV ([references in [41]). Multiple stress signals such as hypoxia, stress hormones, and various chemicals have been shown to increase $\Delta \Psi_{\mathrm{m}}$ to high values via increased cytosolic $\mathrm{Ca}^{2+}$ concentrations. This increase of $\Delta \Psi_{\mathrm{m}}$, which occurs often transient, is named "hyperpolarization" of $\Delta \Psi_{\mathrm{m}}$. Numerous studies have demonstrated the hyperpolarization of $\Delta \Psi_{\mathrm{m}}$ by various compounds [77]. The neurotoxic effect of high glucose in diabetes mellitus was studied by Vincent et al. [78] in human SHSY5Y neurons, rat sensory neurons, and Schwann cells. After exposure to $20 \mathrm{mM}$ glucose, an initial transient hyperpolarization of $\Delta \Psi_{\mathrm{m}}$ was measured, followed by an increase of ROS, and finally neuronal death. Mitochondrial hyperpolarization represents an early and reversible step in $\mathrm{T}$ cell activation and apoptosis [79]. Transient high $\Delta \Psi_{\mathrm{m}}$ values have also been described by synthetic cannabinoids in human proximal tubule cells [80], by statins (lovastatin and simvastatin), which increased the $\Delta \Psi_{\mathrm{m}}$ in HepG2 and Huh7 human hepatocarcinoma cells and HCC4006 human lung adenocarcinoma cells [81], and by honokiol, which induced in bladder cancer cells and increase of $\Delta \Psi_{\mathrm{m}}$ and ROS formation, and at high doses apoptotic cell death [82]. Hyperpolarization of $\Delta \Psi_{\mathrm{m}}$ was furthermore shown with protamine sulfate [83] and graphene oxide (a marker for air pollution) [84].

All these compounds increase primarily the cytosolic $\mathrm{Ca}^{2+}$ concentration, followed by mitochondrial ROS formation and eventually followed by apoptosis and cell death. But also psychosocial stress results in the increase of cytosolic $\mathrm{Ca}^{2+}$ concentration, as shown in isolated cardiomyocytes [85], in platelets [86], hippocampal-derived HT22 cells [87], urothelial cells [88], and cardiomyocytes [89]. The neurotoxic effect of glutamate in neurons via the N-methyl-D-aspartat-receptor was related to an increase of cytosolic $\mathrm{Ca}^{2+}$ and the formation of $\operatorname{ROS}[90,91]$.

In the sequence of reactions between stress and multiple diseases, shown in Fig. 1, the step between the increase of cytosolic $\mathrm{Ca}^{2+}$ and hyperpolarization of $\Delta \Psi_{\mathrm{m}}$ was so far unknown in the current literature [5, 6, 92]. The above-reviewed data explains how stress could induce excessive production of ROS in mitochondria by switching off the allosteric ATP inhibition of COX, which under relaxed conditions, keeps $\Delta \Psi_{\mathrm{m}}$ 


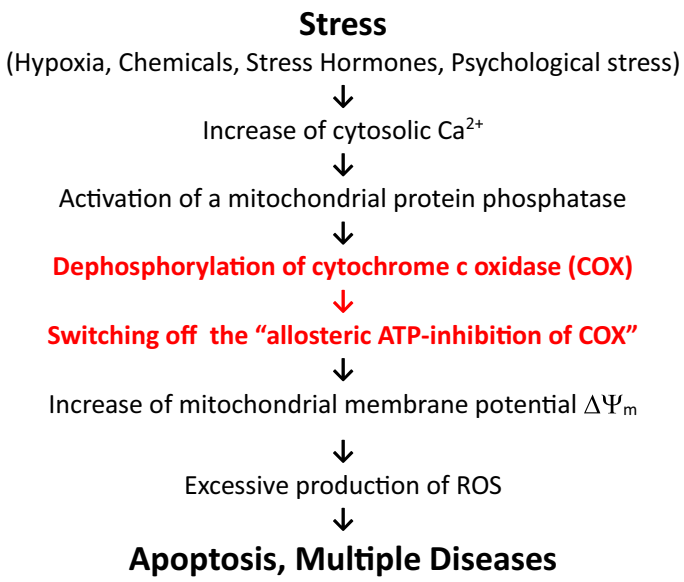

Stress

(Hypoxia, Chemicals, Stress Hormones, Psychological stress) $\downarrow$

Increase of cytosolic $\mathrm{Ca}^{2+}$

$\downarrow$

Activation of a mitochondrial protein phosphatase

$\downarrow$

Dephosphorylation of cytochrome c oxidase (COX)

$\downarrow$

Switching off the "allosteric ATP-inhibition of COX"

$\downarrow$

Increase of mitochondrial membrane potential $\Delta \Psi_{\mathrm{m}}$

$\stackrel{\downarrow}{\downarrow}$ Excessive production of ROS

$\downarrow$

Apoptosis, Multiple Diseases

Fig. 1 From stress to apoptosis and/or multiple diseases, sequences of molecular reactions

at low values (below $130 \mathrm{mV}$ ). The increase of cytosolic $\mathrm{Ca}^{2+}$ concentration by various stress signals from 0.1 to $1-10 \mu \mathrm{M}$ [73] activates a protein phosphatase which dephosphorylates COX and switches off the allosteric ATP inhibition [68, 69], followed by hyperpolarization of $\Delta \Psi_{\mathrm{m}}$ and increased production of ROS.

From these results, we conclude that the health in all higher organisms is based on the maintenance of a low mitochondrial membrane potential $\Delta \Psi_{\mathrm{m}}$ via the "allosteric ATP inhibition of COX," which prevents the formation of high and deleterious amounts of ROS. All types of stress signals which increase the cytosolic $\mathrm{Ca}^{2+}$ concentration, dephosphorylate $\mathrm{COX}$, and switch off the allosteric ATP inhibition, leading to an increased ROS production via increasing the $\Delta \Psi_{\mathrm{m}}$, thus finally resulting in apoptosis, or in the long run to multiple diseases.

\section{Near-infrared light suppresses stroke infarct via inhibition of COX activity}

The physiological significance of the "allosteric ATP inhibition of COX" was recently verified by experiments of Hüttemann and coworkers, who discovered inhibition of COX activity by near-infrared light of 750- and 950-nm wavelength. The near-infrared light reduced the mitochondrial membrane potential $\left(\Delta \Psi_{\mathrm{m}}\right)$, attenuated mitochondrial superoxide production (ROS), and in turn neuronal death of cultured HT22 cells following glutamate exposure and oxygenglucose deprivation [93]. In living animals of a rat stroke model with a longitudinal analysis of brain injury using magnetic resonance imaging, a sustained reduction in infarct volume following ischemic stroke was found after exposure to near-infrared light [94].

These results with living rats coincide with the conclusion derived from results on the allosteric ATP inhibition of COX that attenuation of COX activity prevents the increase of $\Delta \Psi_{\mathrm{m}}$ to values resulting in deleterious mitochondrial ROS production. Another way to decrease $\Delta \Psi_{\mathrm{m}}$ and ROS generation in mitochondria is by using uncoupler of oxidative phosphorylation, which induces a backflow of translocated protons at the inner mitochondrial membrane [95].

\section{Conclusion}

The "allosteric ATP inhibition of COX" is based on the feedback inhibition of COX by ATP, which binds to the matrix side of the "supernumerary" subunit IV. This subunit is lacking in bacteria [96], but it became essential during the evolution of higher organisms, which are characterized by the continuous change between active (state 3 of mitochondrial respiration) and resting state (state 4 of mitochondrial respiration), where $\Delta \Psi_{\mathrm{m}}$ increases. The allosteric ATP inhibition of COX represents an essential mechanism of higher aerobic organisms to avoid the increase of $\Delta \Psi_{\mathrm{m}}$ and thus the formation of deleterious ROS during rest. Without this mechanism, long-living organisms would suffer from various diseases and would die early due to accelerated aging.

Acknowledgements Open Access funding provided by Projekt DEAL.

\section{Compliance with ethical standards}

Conflict of interest There is no potential conflict of interest.

Open Access This article is licensed under a Creative Commons Attribution 4.0 International License, which permits use, sharing, adaptation, distribution and reproduction in any medium or format, as long as you give appropriate credit to the original author(s) and the source, provide a link to the Creative Commons licence, and indicate if changes were made. The images or other third party material in this article are included in the article's Creative Commons licence, unless indicated otherwise in a credit line to the material. If material is not included in the article's Creative Commons licence and your intended use is not permitted by statutory regulation or exceeds the permitted use, you will need to obtain permission directly from the copyright holder. To view a copy of this licence, visit http://creativecommons.org/licenses/by/4.0/.

\section{References}

1. Steptoe A, Kivimäki M (2013) Stress and cardiovascular disease: an update on current knowledge. Annu Rev Public Health 34:337354

2. Dragano N, Siegrist J, Nyberg ST, Lunau T, Fransson EI, Alfredsson L, Bjorner JB, Borritz M, Burr H, Erbel R et al (2017) Effort-reward imbalance at work and incident coronary heart disease. A multicohort study of 90,164 individuals. Epidemiol. 28: 619-626

3. Siegrist J, Sies H (2017) Disturbed redox homeostasis in oxidative distress. A molecular link from chronic psychosocial work stress to coronary heart disease? Circ Res 121:103-105 
4. Schieber M, Chandel NS (2014) ROS function in redox signaling and oxidative stress. Curr Biol 24(10):R453-R462

5. Gracia KC, Llanas-Cornejo D, Husi H (2017) CVD and oxidative stress. J Clin Med 6:22

6. Kiyuna LA, Prestes e Albuquerque R, Chen C-H, Mochly-Rosen D, JCB F (2018) Targeting mitochondrial dysfunction and oxidative stress in heart failure: challenges and opportunities. Free Radic Biol Med 129:155-168

7. Zhou B, Rong Tian R (2018) Mitochondrial dysfunction in pathophysiology of heart failure. J Clin Invest 128(9):3716-3726

8. Dalle-Donne I, Rossi R, Colombo R, Giustarini D, Milzani A (2006) Biomarkers of oxidative damage in human disease. Clin Chem 52:601-623

9. Valko M, Leibfritz D, Moncola J, Cronin MTD, Mazura M, Telser J (2007) Free radicals and antioxidants in normal physiological functions and human disease. Int J Biochem Cell Biol 39:44-84

10. Trachootham D, Zhang H, Zhang W, Feng L, Du M, Zhou Y, Chen Z, Pelicano H, Plunkett W, Wierda WG, Keating MJ, Huang P (2008) Redox regulation of cell survival. Antioxid Redox Signal 10:1343-1374

11. Sabharwal SS, Schumacker PT (2014) Mitochondrial RS in cancer: initiators, amplifiers or an Achilles' heel? Nat Rev Cancer 14(11): 709-721

12. Bannister JV, Bannister WH, Rotilio G (1987) Aspects of the structure, function, and applications of superoxide dismutase. CRC Crit Rev Biochem 22(2):111-180

13. Go YM, Chandler JD, Jones DP (2015) The cysteine proteome. Free Radic Biol Med 84:227-245

14. Ludwig B, Bender E, Arnold S, Hüttemann M, Lee I, Kadenbach B (2001) Cytochrome c oxidase and the regulation of oxidative phosphorylation. ChemBioChem 2:392-403

15. Ray G, Husain SA (2002) Oxidants, antioxidants and carcinogenesis. Indian J Exp Biol 40(11):1213-1232

16. Afonso V, Champy R, Mitrovic D, Collin P, Lomri A (2007) Reactive oxygen species and superoxide dismutases: role in joint diseases. Joint Bone Spine 74(4):324-329

17. Zhang J, Wang X, Vikash V, Ye Q, Wu D, Liu Y, Dong W (2016) ROS and ROS-mediated cellular signaling. Oxidative Med Cell Longev 2016:4350965

18. Forrester SJ, Kikuchi DS, Hernandes MS, Xu Q, Griendling KK (2018) Reactive oxygen species in metabolic and inflammatory signaling. Circ Res 122(6):877-902

19. Moloney JN, Cotter TG (2018) ROS signalling in the biology of cancer. Semin Cell Dev Biol 80:50-64

20. Villani G, Attardi G (2000) In vivo control of respiration by cytochrome c oxidase in human cells. Free Radic Biol Med 29(3-4): 202-210

21. Dalmonte ME, Forte E, Genova ML, Giuffrè A, Sarti P, Lenaz G (2009) Control of respiration by cytochrome c oxidase in intact cells: role of the membrane potential. J Biol Chem 284(47): 32331-32335

22. Chen Y-R, Zweier JL (2014) Cardiac mitochondria and reactive oxygen species generation. Circ Res 114:524-537

23. Murphy MP (2009) How mitochondria produce reactive oxygen species. Biochem J 417:1-13

24. Brand MD (2010) The sites and topology of mitochondrial superoxide production. Exp Gerontol 45(7-8):466-472

25. Lenaz G (2001) Critical Review. The mitochondrial production of reactive oxygen species: mechanisms and implications in human pathology. IUBMB Life 52:159-164

26. Bleier L, Wittig I, Heide H, Steger M, Brandt U, Dröse S (2015) Generator-specific targets of mitochondrial reactive oxygen species. Free Radic Biol Med 78:1-10

27. Zhao R-Z, Jiang S, Zhang L, Yu Z-B (2019) Mitochondrial electron transport chain, ROS generation and uncoupling (review). Int J Mol Med 44:3-15
28. Wong HS, Dighe PA, Mezera V, Monternier PA, Brand MD (2017) Production of superoxide and hydrogen peroxide from specific mitochondrial sites under different bioenergetic conditions. J Biol Chem 292(41):16804-16809

29. Finkel T, Holbrook NJ (2000) Oxidants, oxidative stress and the biology of ageing. Nature 408:239-247

30. Dröge W (2003) Oxidative stress and aging. Adv Exp Med Biol 543:191-200

31. Chance B, Sies H, Boveris A (1979) Hydroperoxide metabolism in mammalian organs. Physiol Rev 59(3):527-605

32. Hafner RP, Nobes CD, McGown AD, Brand MD (1988) Altered relationship between protonmotive force and respiration rate in non-phosphorylating liver mitochondria isolated from rats of different thyroid hormone status. Eur J Biochem 178:511-518

33. Nicholls DG, Ferguson SJ (1992) Bioenergetics, vol 2. Academic Press, London, pp 82-87

34. Liu SS (1997) Generating, partitioning, targeting and functioning of superoxide in mitochondria. Biosci Rep 17:259-272

35. Korshunov SS, Skulachev VP, Starkov AA (1997) High protonic potential actuates a mechanism of production of reactive oxygen species in mitochondria. FEBS Lett 416:15-18

36. Starkov AA, Fiskum G (2003) Regulation of brain mitochondrial $\mathrm{H} 2 \mathrm{O} 2$ production by membrane potential and $\mathrm{NAD}(\mathrm{P}) \mathrm{H}$ redox state. J Neurochem 86(5):1101-1107

37. Rottenberg H, Covian R, Trumpower BL (2009) Membrane potential greatly enhances superoxide generation by the cytochrome bc1 complex reconstituted into phospholipid vesicles. J Biol Chem 284: 19203-19210

38. Knorre DA, Severin FF (2016) Uncouplers of oxidation and phosphorylation as antiaging compounds. Biochem Mosc 81(12):14381444

39. Cadenas S (2018) Mitochondrial uncoupling, ROS generation and cardioprotection. Biochim Biophys Acta Bioenerg 1859:940-950

40. Hüttemann M, Lee I, Pecinova A, Pecina P, Przyklenk K, Doan JW (2008) Regulation of oxidative phosphorylation, the mitochondrial membrane potential, and their role in human disease. J Bioenerg Biomembr 40:445-456

41. From AHL, Zimmer SD, Michurski SP, Mohanakrishnan P, Ulstad VK, Thoma WJ, Ugurbil K (1990) Regulation of the oxidative phosphorylation rate in the intact cell. Biochemistry 29:3731-3743

42. Arnold S, Kadenbach B (1997) Priority Paper. Cell respiration is controlled by ATP, an allosteric inhibitor of cytochrome c oxidase. Eur J Biochem 249:350-354

43. Arnold S, Kadenbach B (1999) The intramitochondrial ATP/ADPratio controls cytochrome $\mathrm{c}$ oxidase activity allosterically. FEBS Lett 443:105-108

44. Griendling KK, Touyz RM, Zweier JL, Dikalov S, Chilian W, Chen YR, Harrison DG, Bhatnagar A (2016) Measurement of reactive oxygen species, reactive nitrogen species, and redox-dependent signaling in the cardiovascular system: a scientific statement from the American Heart Association. Circ Res 119(5):e39-e75

45. Kadenbach B, Hüttemann M (2015) The subunit composition and function of mammalian cytochrome c oxidase. Mitochondrion 24: 64-76

46. Sinkler CA, Kalpage H, Shay J, Lee I, Malek MH, Grossman LI, Hüttemann M (2017) Tissue- and condition-specific isoforms of mammalian cytochrome $\mathrm{c}$ oxidase subunits: from function to human disease. Oxidative Med Cell Longev 2017:1534056

47. Covian R, Balaban RS (2012) Cardiac mitochondrial matrix and respiratory complex protein phosphorylation. Am J Physiol Heart Circ Physiol 303:H940-H966

48. Helling S, Hüttemann M, Ramzan R, Kim SH, Lee I, Müller T, Langenfeld E, Meyer HE, Kadenbach B, Vogt S, Marcus K (2012) Multiple phosphorylations of cytochrome c oxidase and their functions. Proteomics 12:950-959 
49. Hüttemann M, Lee I, Grossman LI, Doan JW, Sanderson TH (2012) Phosphorylation of mammalian cytochrome $\mathrm{c}$ and cytochrome $\mathrm{c}$ oxidase in the regulation of cell destiny: respiration, apoptosis, and human disease. Adv Exp Med Biol 748:237-264

50. Liko I, Degiacomi MT, Mohammed S, Yoshikawa S, Schmidt C, Robinson CV (2016) Dimer interface of bovine cytochrome c oxidase is influenced by local posttranslational modifications and lipid binding. Proc Natl Acad Sci U S A 113:8230-8235

51. Kadenbach B (2017) Regulation of mammalian 13-subunit cytochrome c oxidase and binding of other proteins. Role of NDUFA4. Trends Endocrinol Metab 28:761-770

52. Schägger H, Pfeiffer K (2000) Supercomplexes in the respiratory chains of yeast and mammalian mitochondria. EMBO J 19(8): 1777-1783

53. Althoff T, Mills J, Popot J-L, Kühlbrandt W (2011) Arrangement of electron transport chain components in bovine mitochondrial supercomplex I1III2IV1. EMBO J 30:4652-4664

54. Letts JA, Fiedorczuk K, Sazanov LA (2016) The architecture of respiratory supercomplexes. Nature 537:644-648

55. Sousa JS, Mills DJ, Vonck J, Kühlbrandt W (2016) Functional asymmetry and electron flow in the bovine respirasome. elife 5 https://doi.org/10.7554/eLife.21290.

56. Napiwotzki J, Kadenbach B (1998) Extramitochondrial ATP/ADPratios regulate cytochrome $\mathrm{c}$ oxidase activity via binding to the cytosolic domain of subunit IV. Biol Chem 379:335-339

57. Arnold S, Goglia F, Kadenbach B (1998) 3,5-Diiodothyronine binds to subunit Va of cytochrome c oxidase and abolishes the allosteric inhibition of respiration by ATP. Eur J Biochem 252: 325-330

58. Vygodina TV, Mukhaleva E, Azarkina NV, Konstantinov AA (2017) Cytochrome $c$ oxidase inhibition by calcium at physiological ionic composition of the medium: implications for physiological significance of the effect. Biochim Biophys Acta 1858(12):982990

59. Hüttemann M, Kadenbach B, Grossman LI (2001) Mammalian subunit IV isoforms of cytochrome c oxidase. Gene 267:111-123

60. Napiwotzki J, Shinzawa-Itoh K, Yoshikawa S, Kadenbach B (1997) ATP and ADP bind to cytochrome $\mathrm{c}$ oxidase and regulate its activity. Biol Chem 378:1013-1021

61. Tsukihara T, Aoyama H, Yamashita E, Tomizaki T, Yamaguchi H, Shinzawa-Itoh K, Nakashima R, Yaono R, Yoshikawa S (1996) The whole structure of the 13-subunit oxidized cytochrome $\mathrm{c}$ oxidase at 2.8 Å. Science 272:1136-1144

62. Osuda Y, Shinzawa-Itoh K, Tani K, Maeda S, Yoshikawa S, Tsukihara T, Gerle C (2016) Two dimensional crystallization of monomeric bovine cytochrome $\mathrm{c}$ oxidase with bound cytochrome $\mathrm{c}$ in reconstituted lipid membranes. Microscopy(Oxf) 65(3):263267

63. Kaim G, Dimroth P (1999) ATP synthesis by F-type ATP synthase is obligatorily dependent on the transmembrane voltage. EMBO J 18:4118-4127

64. Ramzan R, Staniek K, Kadenbach B, Vogt S (2010) Mitochondrial respiration and membrane potential are regulated by the allosteric ATP-inhibition of cytochrome c oxidase. Biochim Biophys Acta 1797:1672-1680

65. Kadenbach B, Hüttemann M, Arnold S, Lee I, Mühlenbein N, Bender E (2000) Mitochondrial energy metabolism is regulated via nuclear-coded subunits of cytochrome c oxidase. Free Radic Biol Med 29:211-221

66. Kadenbach B, Ramzan R, Wen L, Vogt S (2010) New extension of the Mitchell theory for oxidative phosphorylation in mitochondria of living organisms. Biochim Biophys Acta 1800:205-212

67. Helling S, Vogt S, Rhiel A, Ramzan R, Wen L, Marcus K, Kadenbach B (2008) Phosphorylation and kinetics of mammalian cytochrome c oxidase. Mol Cell Proteomics 7(9):1714-1724
68. Lee I, Bender E, Arnold S, Kadenbach B (2001) Minireview-hypothesis. New control of mitochondrial membrane potential and ROS-formation. Biol Chem 382:1629-1633

69. Lee I, Bender E, Kadenbach B (2002) Control of mitochondrial membrane potential and ROS formation by reversible phosphorylation of cytochrome c oxidase. Mol Cell Biochem 234(235):63-70

70. Ramzan R, Rhiel A, Weber P, Kadenbach B, Vogt S (2019) Reversible dimerization of cytochrome c oxidase regulates mtochondrial respiration. Mitochondrion 49:149-155

71. Kalpage HA, Bazylianska V, Recanati MA, Fite A, Liu J, Wan J, Mantena N, Malek MH, Podgorski I, Heath EI, Vaishnav A, Edwards BF, Grossman LI, Sanderson TH, Lee I, Hüttemann M (2019) Tissue-specific regulation of cytochrome c by posttranslational modifications: respiration, the mitochondrial membrane potential, ROS, and apoptosis. FASEB J 33(2):1540-1553

72. Carafoli E, Krebs J (2016) Why calcium? How calcium became the best communicator. J Biol Chem 291(40):20849-20857

73. Kass GE, Orrenius S (1999) Calcium signaling and cytotoxicity. Environ Health Perspect 107(Suppl 1):25-35

74. Vicencio JM, Estrada M, Galvis D, Bravo R, Contreras AE, Rotter D, Szabadkai G, Hill JA, Rothermel BA, Jaimovich E, Lavandero S (2011) Anabolic androgenic steroids and intracellular calcium signaling: a mini review on mechanisms and physiological implications. Mini-Rev Med Chem 11(5):390-398

75. Gaspers LD, Pierobon N, Thomas AP (2019) Intercellular calcium waves integrate hormonal control of glucose output in the intact liver. J Physiol 597(11):2867-2885

76. Trebak M, Kinet JP (2019) Calcium signalling in T cells. Nat Rev Immunol 19(3):154-169

77. Kadenbach B, Arnold S, Lee I, Hüttemann M (2004) The possible role of cytochrome c oxidase in stress-induced apoptosis and degenerative diseases. Biochim Biophys Acta 1655:400-408

78. Vincent AM, Brownlee M, Russell JW (2002) Oxidative stress and programmed cell death in diabetic neuropathy. Ann N Y Acad Sci 959:368-383

79. Perl A, Gergely P Jr, Nagy G, Koncz A, Banki K (2004) Mitochondrial hyperpolarization: a checkpoint of T-cell life, death and autoimmunity. Trends Immunol 25(7):360-367

80. Silva JP, Araújo AM, de Pinho PG, Carmo H, Carvalho F (2019) Synthetic cannabinoids JWH-122 and THJ-2201 disrupt endocannabinoid-regulated mitochondrial function and activate apoptotic pathways as a primary mechanism of in vitro nephrotoxicity at in vivo relevant concentrations. Toxicol Sci 169(2):422-435

81. Christie CF, Fang D, Hunt EG, Morris ME, Rovini A, Heslop KA, Beeson GC, Beeson CC, Maldonado EN (2019) Statin-dependent modulation of mitochondrial metabolism in cancer cells is independent of cholesterol content. FASEB J 33(7):8186-8201

82. Hsiao CH, Yao CJ, Lai GM, Lee LM, Whang-Peng J, Shih PH (2019) Honokiol induces apoptotic cell death by oxidative burst and mitochondrial hyperpolarization of bladder cancer cells. Exp Ther Med 17(5):4213-4222

83. Ramzan R, Michels S, Weber P, Rhiel A, Irqsusi M, Rastan AJ, Culmsee C, Vogt S (2019) Protamine sulfate induces mitochondrial hyperpolarization and a subsequent increase in reactive oxygen species production. J Pharmacol Exp Ther 370(2):308-317

84. Arbo MD, Altknecht LF, Cattani S, Braga WV, Peruzzi CP, Cestonaro LV, Göethel G, Durán N, Garcia SC (2019) In vitro cardiotoxicity evaluation of graphene oxide. Mutat Res 841:8-13

85. Turdi S, Yuan M, Leedy GM, Wu Z, Ren J (2012) Chronic social stress induces cardiomyocyte contractile dysfunction and intracellular Ca2+ derangement in rats. Physiol Behav 105(2):498-509

86. Matsuhisa F, Kitamura N, Satoh E (2014) Effects of acute and chronic psychological stress on platelet aggregation in mice. Stress 17(2):186-192 
87. Solanki N, Salvi A, Patki G, Salim S (2017) Modulating oxidative stress relieves stress-induced behavioral and cognitive impairments in rats. Int J Neuropsychopharmacol 20(7):550-561

88. Kullmann FA, McDonnell BM, Wolf-Johnston AS, Kanai AJ, Shiva S, Chelimsky T, Rodriguez L, Birder LA (2019) Stressinduced autonomic dysregulation of mitochondrial function in the rat urothelium. Neurourol Urodyn 38(2):572-581

89. Barbiero S, Aimo A, Castiglione V, Giannoni A, Vergaro G, Passino C, Emdin M (2018) Healthy hearts at hectic pace: from daily life stress to abnormal cardiomyocyte function and arrhythmias. Eur J Prev Cardiol 25(13):1419-1430

90. Reynolds IJ, Hastings TG (1995) Glutamate induces the production of reactive oxygen species in cultured forebrain neurons following NMDA receptor activation. J Neurosci 15:3318-3327

91. Dugan LL, Sensi SL, Canzoniero LM, Handran SM, Lin TS, Goldberg MP (1995) Mitochondrial production of reactive oxygen species in cortical neurons following exposure to N-methyl-D-aspartate. J Neurosci 15:6377-6388

92. Kuznetsov AV, Javadov S, Margreiter R, Grimm M, Hagenbuchner J, Ausserlechner MJ (2019) The role of mitochondria in the mechanisms of cardiac ischemia-reperfusion injury. Antioxidants (Basel) 8(10):E454
93. Sanderson TH, Wider JM, Lee I, Reynolds CA, Liu J, Lepore B, Tousignant R, Bukowski MJ, Johnston H, Fite A, Raghunayakula S, Kamholz J, Grossman LI, Przyklenk K, Hüttemann M (2018) Inhibitory modulation of cytochrome $c$ oxidase activity with specific near-infrared light wavelengths attenuates brain ischemia/ reperfusion injury. Sci Rep 8:3481

94. Strubakos CD, Malik M, Wider JM, Lee I, Reynolds CA, Mitsias P, Przyklenk K, Hüttemann M, Sanderson TH (2019) Non-invasive treatment with near-infrared light: a novel mechanisms-based strategy that evokes sustained reduction in brain injury after stroke. $\mathrm{J}$ Cereb Blood Flow Metab 1-12

95. Demine S, Renard P, Arnould T (2019) Mitochondrial uncoupling: a key controller of biological processes in physiology and diseases. Cells 8:795

96. Follmann K, Arnold S, Ferguson-Miller S, Kadenbach B (1998) Cytochrome c oxidase activity from eucaryotes but not from procaryotes is allosterically inhibited by ATP. Biochem Mol Biol Int 45:1047-1055

Publisher's note Springer Nature remains neutral with regard to jurisdictional claims in published maps and institutional affiliations. 